\title{
CIÊNCIAPNATURA 35䇾
}

\section{Mapeamento do uso do solo na bacia hidrográfica do rio Quaraí sob a perspectiva da orizicultura e a demanda de água associada nas porções brasileira e uruguaia}

\author{
Mapping of ground use of the Quaraí watershed under the rice production perspec- \\ tive and water demand associated with Brazilian and Uruguayan portions
}

\author{
Daniel Junges Menezes ${ }^{1}$,Romario Trentin ${ }^{2}$ \\ ${ }^{1}$ Doutorando em geografia e geociências - PPGGEO/UFSM - UFSM \\ Doutor, Departamento de Geociências. UFSM, RS brasil
}

\begin{abstract}
Resumo
A demanda de recursos hídricos em bacias hidrográficas transfronteiriças tem gerado problemas de gestão complexos. O aumento das áreas de cultivo de arroz irrigado na bacia hidrográfica do Rio Quaraí, localizado na porção meridional do Brasil, fazendo fronteira com o Uruguai, tem desencadeado uma importante questão a respeito da demanda de água e a gestão integrada entre estes dois países. O objetivo do trabalho foi problematizar a respeito da gestão transfronteiriça da bacia hidrográfica do rio Quarai, tendo como foco a orizicultura, cuja distribuição espacial, pode ser observada a partir do mapa de uso do solo, que ilustra diferenças na intensidade de uso nas porções brasileira e uruguaia. A metodologia consistiu no uso de imagens do satélite Landsat-5 TM, de 2011, para a elaboração de um mapa de uso do solo, baseado na classificação supervisionada por máxima verossimilhança (Maxver). O mapeamento permitiu analisar de forma espacial a questão desta demanda, nas porções brasileira e uruguaia da bacia hidrográfica. Constatou-se que o uso predominante na bacia hidrográfica é de campos e pastagens $(72,4 \%$ ou 1060487,926 ha). Entretanto, quando realizada uma análise separada das porções brasileira (que representa $46 \%$ da área total) e uruguaia (54\% da área total) se observou que o uso, principalmente associado à orizicultura, é mais intenso na porção brasileira onde figura 19,9\% contra 15,8\% da segunda. Assim, a demanda por água para suprir o cultivo na porção brasileiraé maior, embora territorialmente seja menor que a porção uruguaia, apresenta um maior uso associado a lavouras.
\end{abstract}

Palavras-chave: Bacia hidrográfica; Uso do solo; Rio Quaraí;

\begin{abstract}
The demand of water resources in transboundary watersheds s has generated complex management problems. Increased areas of irrigated rice in Quarai River basin, located in the southern portion of Brazil, bordering Uruguay, has triggered an important issue regarding the water demand and integrated management between two countries. The objective was to discuss on the issue of transboundary river basin management Quarai the river, with a focus on rice production, whose spatial distribution can be observed from the land use map, which illustrates differences in the intensity of use in Brazilian and Uruguayan portions. The methodology consisted of using satellite images Landsat- 5 TM 2011 for the preparation of a land use map based on supervised classification by maximum likelihood (Maxver). The mapping allowed us to analyze spatial form of the issue of this demand, the Brazilian and Uruguayan portions of the watershed. It was found that the predominant use in the watershed is of fields and pastures $(72.4 \%$ or $1,060,487.926 \mathrm{ha})$. However, when performed a separate analysis of the Brazilian portions ( representing $46 \%$ of total area) and Uruguay ( $54 \%$ of total area) was observed that the use, mainly associated with rice cultivation is most intense in the Brazilian portion of figure 19.9 where \% against $15.8 \%$ in the second. Thus, the demand for water to meet the crop in Brazil's portion is larger, although territorially smaller than the Uruguayan portion has a greater use associated with crops.
\end{abstract}

Keywords: Watershed, Land Use; River Quaraí; 


\section{Introdução}

No passado, o avanço da população em direção a novos espaços ocorria atrelado à presença de rios. Aproveitavam-se dos recursos hídricos para a irrigação dos campos agrícolas e o abastecimento das cidades, que em sua maioria, localizavam-se às margens dos cursos d'água. Cidades localizadas nas margens dos rios Tigre e Eufrates, na Mesopotâmia surgiram, assim como no rio Nilo, no Egito, onde foram desenvolvidas técnicas que proporcionassem meios de controlar as cheias na estação chuvosa, e a irrigação das terras cultiváveis na estação seca RIGHI (2010).

Essa relação do homem com os cursos d'água, assim como a ocupação de sua planície de inundação se dava fundamentada em certo conhecimento de sua dinâmica, o que hoje se torna cada vez mais importante, tendo em vista a crescente demanda e pressão sobre os recursos hídricos.

A gestão de recursos hídricos compreende a um conjunto de ações destinadas a regular o uso, o controle e a proteção dos recursos hídricos, em conformidade com a legislação e normas pertinentes e integra projetos e atividades com o objetivo de promover a recuperação e a preservação da qualidade e quantidade dos recursos das bacias hidrográficas.

Na mesma perspectiva devem ser geridos os recursos hídricos que estão na condição de transfronteiriços, e submetidos à interesses e ações de distintos territórios, embora sujeitos a questões associadas a temas como demanda e disponibilidade, atividades econômicas e qualidade ambiental e ainda trâmites políticos, emergem como temas de litígio mas também de objetivo comum ao entendimento.

Para Tucci, (2006 p.9) os mecanismos para a gestão destas bacias hidrográficas se baseiam em condicionantes e princípios, onde podemos citar: Bacia transfronteiriça: quando mais de um país compartilha uma mesma bacia hidrográfica; A independência e soberania dos países: tomada de decisão em cada território é de atribuição dos Estados (países); O complexo conjunto de interesses de vários países: os interesses de desenvolvimento econômico, social e ambiental e estratégias de cada sociedade dentro de um universo globalizado; A dimensão espacial e temporal dos recursos hídricos: variabilidade e modificação climática da disponibilidade hídrica que atua com base da infraestrutura e conservação ambiental.

Conforme o Programa das Nações Unidas para o Desenvolvimento - PNUD (2006), as águas transfronteiriças estendem a interdependência hidrológica para além das fronteiras nacionais, ligando consumidores de diferentes países dentro de um sistema partilhado. Gerir essa interdependência constitui um dos grandes desafios de desenvolvimento humano que a comunidade internacional enfrenta, sendo que a relação de cooperação entre países tende a ser uma alternativa para superá-lo.

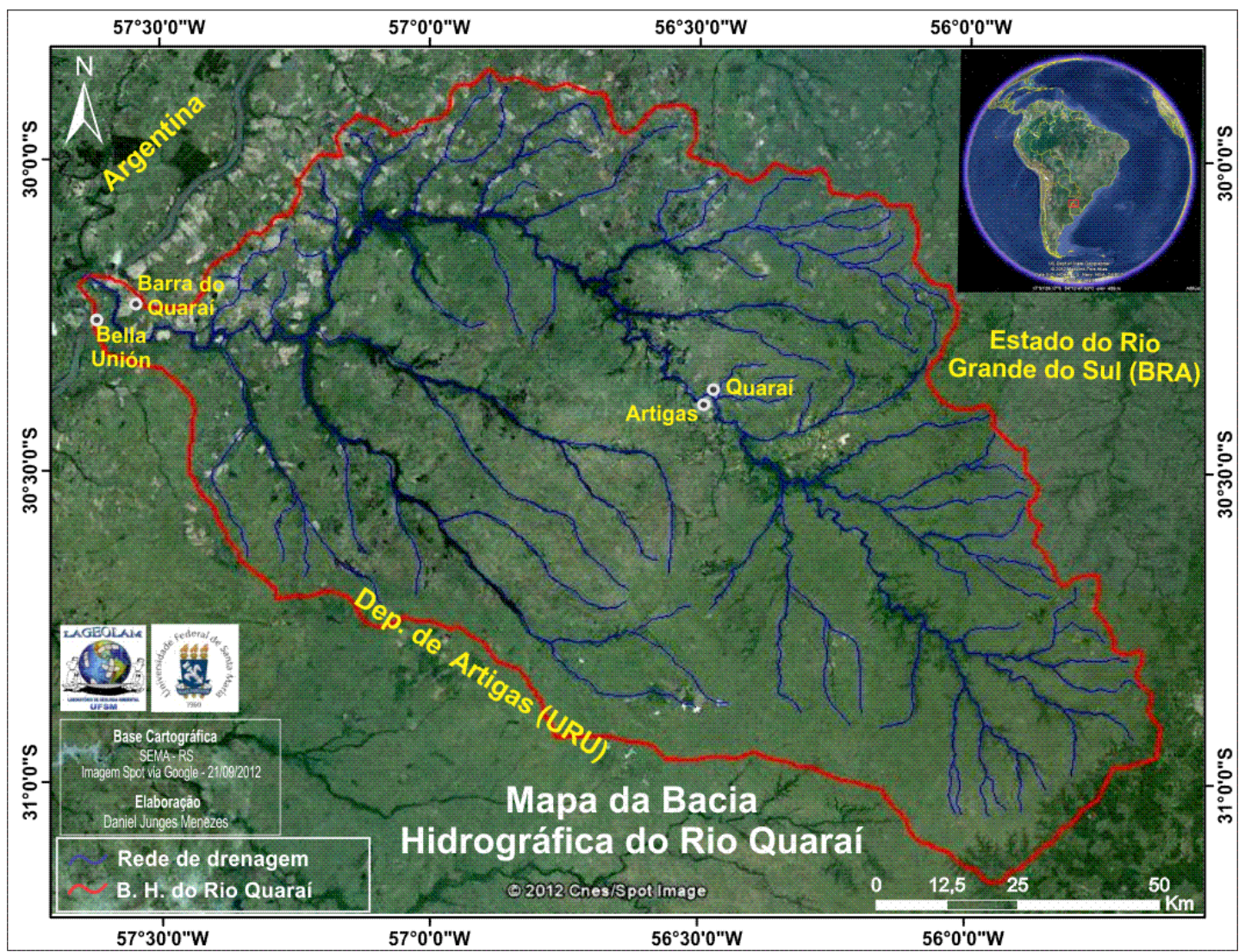

Figura 1 - Mapa de localização da Bacia Hidrográfica do Rio Quaraí 
Se a gestão das águas transfronteiriças for tratada de uma forma mais cooperante, isso poderá produzir ganhos reais em termos de desenvolvimento humano. Poderá reforçar-se a segurança do acesso à água por parte das pessoas mais vulneráveis de ambos os lados da fronteira, melhorando assim a qualidade, a quantidade e o grau de previsibilidade dos fluxos que atravessam os diversos países (PNUD 2006. p.204).

O Brasil possui setenta e quatro cursos d'água classificados como transfronteiriços, sendo possível ressaltar que $60 \%$ do território nacional encontra-se situado nas bacias desses rios (BRASIL, 2006, p. 101).

Dentre estas bacias hidrográficas, temos a do rio Quaraí (Cuareim, em espanhol), situado no extremo sul do Brasil e extremo noroeste do Uruguai (Figura 1), cujo eixo estabelece a fronteira física entre o estado do Rio Grande do Sul no, Brasil, abrangendo os municípios de Barra do Quaraí, Santana do Livramento, Quaraí e Uruguaiana e o e o Departamento de Artigas no Uruguai.

Arcelus et al (1999 apud. CALHMAN, 2008) destacam que "na parte baixa da bacia do Quaraí (também para seus principais afluentes) ocorrem solos profundos com boa vocação para o cultivo de arroz por seu alto conteúdo de argila e boa fertilidade." A autora ainda destaca que

Há mais de duas décadas, começou-se a cultivar, de forma incipiente, áreas irrigadas de arroz nas proximidades das cidades de Artigas e Quaraí. A partir desta data, houve um constante crescimento do cultivo do arroz, determinando, assim, uma demanda cada vez maior do recurso hídrico, que a princípio foi satisfeita através da extração direta do Rio Quaraí e de seus afluentes, a partir de sistemas de bombeamento.

A disponibilidade hídrica nos meses de irrigação (novembro a fevereiro), rapidamente passou a ser um fator limitante para a manutenção da taxa de crescimento da área cultivada (CALHMAN, 2008, p. 139).

Entretanto, há disparidade entre os dois países na produção de arroz, e consequentemente na demanda de água, sendo que na safra 2005/2006 do montante de 72.340 ha de arroz irrigado, apenas 30\% correspondia à porção uruguaia. Tucci (2004, p. 116), ressalva que "na bacia do rio Quarai, na margem uruguaia a demanda é atendida com 50\% das vazões médias mensais, mas não é sustentável considerando o lado brasileiro que tem forte demanda".

Collischonn \& Collischonn (2009) reforçam que algumas bacias hidrográficas no sul do Brasil, podem apresentar balanço hídrico crítico, devido ao fato de boa parte da produção nacional de arroz se situar nesta região, mesmo que em comparação a outras regiões do país, apresentem disponibilidades hídricas relativamente altas.

No que se refere a grande demanda, em função da orizicultura Collischonn, (2011, p.119) aponta que
Bacias em que o uso intensivo de água para irrigação é tão longo quanto as próprias séries hidrológicas também são muito comuns. Na região Sul do Brasil, a atividade agrícola que apresenta o maior consumo de água é a cultura de arroz irrigado. Esta cultura, presente na região desde o início do século $X X$, apresenta uma demanda muito grande de água que, em geral, não pode ser suprida apenas pela vazão dos rios durante os meses de primavera-verão, que é a época da atividade (COLLISCHONN, 2011, p.119).

Da mesma forma, a disponibilidade de informações confiáveis referentes às tipologias de culturas presentes, áreas plantadas e distribuição espacial dentro de uma determinada região são fundamentais na tomada de decisão para o planejamento, assim como a definição de prioridades ou liberação de financiamentos pelos setores envolvidos na agricultura, sejam públicos ou privados, conforme Sano et al. (1998). Segundo os mesmos autores, a obtenção destas informações podem se estabelecer por métodos convencionais como questionários aplicados diretamente aos produtores, ou ainda, por sensoriamento remoto. Rocha (1978) apud Ciroline (2008) aponta que através do levantamento de uso da terra, além de se conhecer a degradação causada no ambiente pelas transformações resultantes da ação antrópica é um levantamento necessário à compreensão dos padrões de organização do espaço em constantes transformações.

Com o avanço das geotecnologias os estudos relacionados ao espaço ficaram mais eficientes e também já não se faz necessário um grande conhecimento teórico para a confecção de cartogramas e as operações associadas a esta prática que indiquem as características do espaço geográfico.

O geoprocessamento, configurando-se pelo uso de técnicas, tanto matemáticas, quanto computacionais para o tratamento de informações geográficas, possui instrumentos computacionais conhecidos como Sistemas de Informações Geográficas (SIG). Estes sistemas permitem a realização de análises complexas, devido à possibilidade de integração de dados de diversas fontes e da criação de um banco de dados georreferenciado. (CÂMARA; MEDEIROS, 1996).

Nesta perspectiva, Ferreira (2008) aponta que o geoprocessamento permite que as informações gerem respostas rápidas e confiáveis que subsidiam a tomada de decisão. Por sua vez, o mapeamento de uso do solo permite tanto a análise espacial quanto quantitativa, sendo uma ferramenta importante na caracterização da área de estudo e fenômenos analisados.

Diante desta premissa, o que este artigo objetiva problematizar a respeito da gestão transfronteiriça da bacia hidrográfica do rio Quaraí, tendo como foco a orizicultura, atividade que exige grande demanda dos recursos hídricos, estabelecida principalmente no baixo curso da bacia e cuja distribuição espacial, pode ser observada a partir do mapa de uso do solo, que ilustra diferenças na intensidade de uso nas porções brasileira e uruguaia. 


\section{Metodologia de trabalho}

O levantamento inicial de informações se deu em diferentes órgãos, tanto brasileiros como internacionais, como a SEMA (Secretaria Estadual de Meio Ambiente), IBGE (Instituto Brasileiro de Geografia e Estatística), DINARA (Direccion Nacional De Recursos Acuaticos), ANA (Agencia Nacional das Águas), USGS (United States Geological Survey), CCL/CRQ (Comitê de Coordenação Local da Comissão Mista Brasileiro-Uruguaia para o Desenvolvimento da Bacia do Rio Quaraí) CIC (Comitê Intergovernamental Coordenador dos Países da Bacia do rio da Prata), entre outros.

A confecção de um mapa de uso do solo da bacia hidrográfica foi elaborado com o intuito de uma melhor caracterização da atividade de cultivo de arroz irrigado, assim como permitiu apontar as diferenças que existem quanto a área cultivada em ambas às porções e consequentemente, diferentes demandas a respeito do uso da água.

Para estruturar o banco de dados georreferenciados que propiciou a geração do mapa de uso do solo, foram obtidas duas imagens Landsat 5 TM, obtidas gratuitamente a partir do USGS, de resolução espacial de 30 metros. A necessidade de se utilizar duas imagens se deu em função da configuração e extensão da bacia hidrográfica, sendo uma imagem datada de 06/09/2011, recobrindo a porção jusante e outra datada de 15/09/2011, recobrindo a porção montante da bacia hidrográfica, com órbitas ponto 224/81 e 223/81, respectivamente. As imagens foram escolhidas por serem recentes e atenderem melhor ao critério de qualidade em termos de cobertura de nuvens.

Após realizado o mosaico das duas imagens TM, foi realizada a classificação de uso do solo. Utilizou-se a interpretação visual para selecionar amostras para a classificação supervisionada Maxver - máxima verossimilhança.

Para auxiliar na atividade coleta das amostras, utilizaram-se ainda imagens de datas distintas e diferentes composições coloridas, em função da grande variabilidade da reflectância das lavouras de arroz entre os períodos de cultivo (outubro a março) e entressafra (abril a setembro), conforme metodologia sugerida por Collischonn \& Collischonn (2009) em estudo anterior na mesma bacia hidrográfica. Foram coletadas 25 amostras para cada um dos alvos de interesse.

Na classificação foram consideradas cinco classe de uso/cobertura do solo: água, compondo os cursos d'agua e pequenos reservatórios; mata, consistindo de vegetação arbórea de maior porte, podendo ser de remanescentes naturais ou de reflorestamento; campos e pastagens, consistindo de vegetação natural de campo, ou então de vegetação em reconstituição, como vegetação secundária formada por gramíneas; lavouras, representadas principalmente por lavouras de arroz junto às drenagens; solo exposto, abrangendo tanto áreas de cultivo estágio de preparo, como também areais e principalmente as áreas urbanizadas e estradas. A classe "nuvens" embora restrita a pequena porção da área também foi incorporada com o intuito de minimizar erros de classificação. A validação desta classificação de deu com a utilização de imagens de melhor detalhe disponíveis via Google Earth Pro. e a utilização da matriz de confusão/erro - Indice de Kappa.

Uma base cartográfica de drenagens disponível através da ANA foi utilizada em função de contemplar drenagens em ambos os países. O primeiro passo diante esta dessa base de dados foi verificar se a hidrografia representada correspondia à drenagem atual. Para isso, foram utilizadas imagens de melhor resolução espacial, via software Google Earth Pro.

Utilizou-se o software ENVI 4.8, desenvolvido pela Exelis VIS, para coleta de amostras, classificação de imagens e validação da mesma e o software Arcgis 10.0 desenvolvido pela ESRI, para o processamento dos dados.

\section{Resultados}

\subsection{Matriz de Confusão e Índice Kappa}

A análise da classificação por meio do Índice Kappa permite averiguar a fidelidade da classificação supervisionada, por meio de uma avaliação de concordância

Tabela 1. Matriz de confusão e resultado do Índice Kappa da classificação de uso de solo na bacia hidrográfica do rio Quaraí.

\begin{tabular}{|c|c|c|c|c|c|c|c|}
\hline Classe & Solo exposto & Arbórea & Campos & Água & Lavoura & Núvens & Total \\
\hline Não Classificado & 0.00 & 0.00 & 0.00 & 0.00 & 0.00 & 0.00 & 0.00 \\
\hline Solo exposto & 92.96 & 0.00 & 0.00 & 0.00 & 41.71 & 0.00 & 12.28 \\
\hline Vegetação Arbórea & 0.00 & 100.00 & 0.00 & 0.04 & 0.42 & 0.00 & 11.54 \\
\hline Campos e Pastagens & 4.93 & 0.00 & 100.00 & 0.00 & 6.85 & 0.00 & 13.42 \\
\hline Água & 0.00 & 0.00 & 0.00 & 99.92 & 0.00 & 0.00 & 48.55 \\
\hline Lavoura & 2.11 & 0.00 & 0.00 & 0.04 & 51.02 & 0.00 & 11.93 \\
\hline Núvens & 0.00 & 0.00 & 0.00 & 0.00 & 0.00 & 100.00 & 2.28 \\
\hline Total & 100.00 & 100.00 & 100.00 & 100.00 & 100.00 & 100.00 & 100.00 \\
\hline \multicolumn{8}{|c|}{ Acurácia (Overall Accuracy) $=88.3844 \%$} \\
\hline \multicolumn{8}{|c|}{ Índice Kappa $=0.8349$} \\
\hline
\end{tabular}


entre as amostras de treinamento e da imagem classificada em comparação a uma nova amostragem e não utilizada na classificação. Da mesma forma, a matriz de confusão (Tabela 1) permite averiguar os possíveis equívocos de classificação em relação às classes estabelecidas.

A matriz de confusão gerada a partir da imagem classificada da bacia hidrográfica, apontou que obteve-se um excelente grau de aceitação nos índices de acurácia da identificação dos alvos $(0,8349)$, conforme os parâmetros de Landis e Koch (1977), que podem ser observados na Tabela 2.

Tabela 2.

\begin{tabular}{cl}
\hline Índice Kappa & Concordância \\
\hline$<0$ & Sem concordância \\
0.00 a 0.19 & Pobre \\
0.20 a 0.39 & Fraca \\
0.40 a 0.59 & Moderada \\
0.60 a 0.79 & Forte \\
0.80 a 1.00 & Excelente \\
\hline
\end{tabular}

Fonte: Landis e Koch (1977)

Todavia, ocorreram algumas confusões de classes, principalmente quanto ao solo exposto e áreas de cultivo, tendo em visto que a primeira esteve inclusa na segunda, de maneira geral, caracterizando um erro de comissão ou inclusão, onde são atribuídos a uma determinada classe e erros de classificação das outras classes. Isso se deu devido a muitas das áreas atribuídas como solo exposto, estarem na condição de preparo para cultivo, confusão não ocorrida com áreas urbanizadas ou areais, onde não se observou o mesmo erro.

\subsection{O uso do solo na bacia hidrográfica do rio Quaraí}

A bacia hidrográfica possui área total de $14.657 \mathrm{~km}^{2}$, sendo $46 \%$ em território brasileiro e $54 \%$ em território uruguaio. As demandas para o setor agropecuário, abastecimento urbano e preocupações ambientais são motivo de disputa e busca de soluções, contextualizadas a bacia hidrográfica do rio Quaraí, entre estes dois países.

O mapeamento de uso do solo da bacia hidrográfica aponta que a classe de uso predominante é a de campos e pastagens que representam $72,4 \%$ da área total. Áreas de vegetação arbórea, por sua vez, estão confinadas ao entorno dos corpos hídricos, representadas por matas ripárias e pela atividade de silvicultura, somando 7,9\% da área mapeada. Os corpos d'água representados pelas drenagens também são encontradas nos açudes utilizados para irrigação como também na dessedentação de animais na atividade pecuária, remetendo a 1,6\% da área total. As áreas de lavoura se encontram próximas aos corpos hídricos principais a jusante da bacia hidrográfica, representando $15,8 \%$ da área mapeada. A classe de solo exposto compôs o montante de 2,0\% da bacia hidrográfica.

A partir da Tabela 1, se pode observar algumas diferenças em relação ao uso do solo nas porções uruguaia e brasileira, onde primeiramente evidencia-se que em território brasileiro o uso condicionado à atividades agrícolas fica quase na casa de $20 \%$ do total desta porção da bacia hidrográfica. Por sua vez, essa classe de uso chega a $12 \%$ na porção uruguaia, embora compreenda uma maior área do montante total da bacia hidrográfica. Da mesma maneira a presença de uma maior área representada por corpos d'água em território brasileiro está associada aos reservatórios utilizados para a retenção de água com a finalidade de abastecer as lavouras. Já a maior presença de campos e pastagens na porção uruguaia em relação à brasileira, remete às atividades pastoris predominantes no lado uruguaio.

Quanto aos aspectos socioeconômicos, os municípios inseridos nesta bacia hidrográfica, têm suas atividades produtivas fortemente alicerçadas na pecuária extensiva, no cultivo do arroz irrigado e no pequeno comércio de fronteira. Quanto à distribuição populacional, a bacia apresenta uma concentração da população nas áreas urbanas de Quaraí e Barra do Quaraí (97\%), apresentando no restante da área uma densidade demográfica da ordem de 2 hab/ $\mathrm{km}^{2}$ (VILLANUEVA et al, 2002).

A partir do mapa de uso do solo da bacia hidrográfica (Figura 2), é possível verificar a distribuição espacial das áreas de uso mais intenso para a agricultura, associados a áreas de cultivo de arroz, notoriamente concentradas à jusante e predominantemente na margem direita do curso principal, que remete à porção brasileira. $\mathrm{O}$ aspecto

Tabela 3. Uso do solo na bacia hidrográfica do rio Quaraí para o ano de 2011.

\begin{tabular}{l|rr|r|r|rr}
\hline \multirow{2}{*}{ Uso do Solo } & \multicolumn{2}{|c|}{ Porção brasileira } & \multicolumn{2}{c|}{ Porção uruguai } & \multicolumn{2}{c}{ Bacia hidrográfica } \\
\cline { 2 - 7 } & Área (ha) & \multicolumn{1}{c|}{ \% } & Área (ha) & \multicolumn{1}{c}{$\%$} & Área (ha) & \multicolumn{1}{c}{$\%$} \\
\hline Solo Exposto & 23096,62 & $3,5 \%$ & 6478,294 & $1,0 \%$ & 29574,91 & $2,0 \%$ \\
Vegetação Arbórea & 61165,36 & $9,2 \%$ & 54263,93 & $7,0 \%$ & 115429,3 & $7,9 \%$ \\
Campos e Pastagens & 429964,9 & $64,4 \%$ & 630523 & $79,0 \%$ & 1060488 & $72,4 \%$ \\
Água & 16333,55 & $2,4 \%$ & 7759,27 & $1,0 \%$ & 24092,82 & $1,6 \%$ \\
Lavoura & 132913,6 & $19,9 \%$ & 99140,41 & $12,0 \%$ & 232054 & $15,8 \%$ \\
Núvens & 4061,7615 & $0,6 \%$ & 0 & $0,0 \%$ & 4061,761 & $0,3 \%$ \\
\hline Total & 667535,79 & $100,0 \%$ & 798164,9 & $100,0 \%$ & 1465701 & $100,0 \%$
\end{tabular}




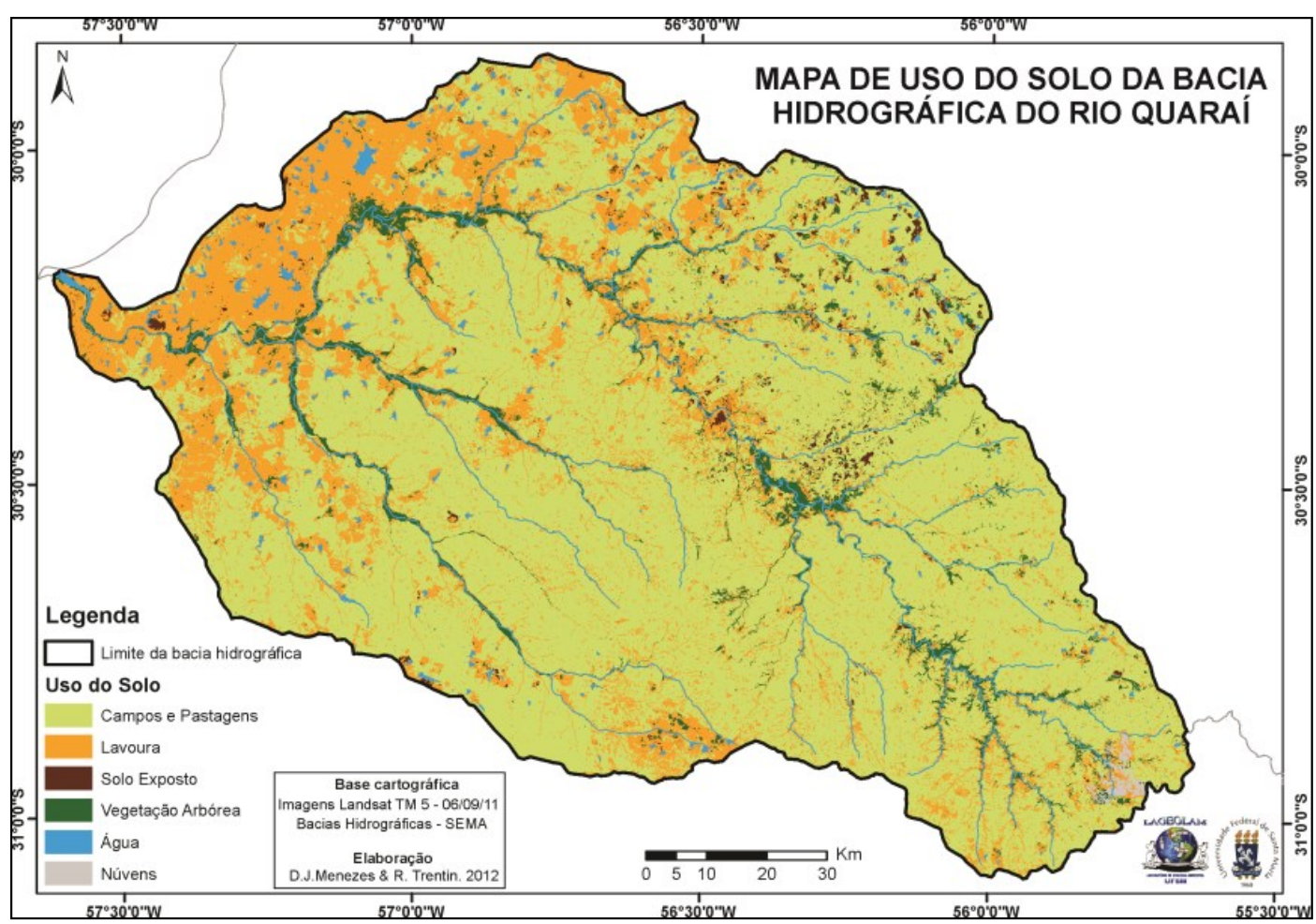

Figura 2. Mapa de uso do solo da bacia hidrográfica do Rio Quaraí, elaborado a partir de imagens Landsat - 5 TM de 2011.

concentrado da orizicultura faz que, na época da irrigação, a expressiva demanda, chegue a esgotar muitos dos cursos de água, sendo que mesmo nas condições hidrológicas normais, os conflitos pelo uso da água são inevitáveis e, na medida que as áreas sob irrigação aumentam, cresce também o potencial de conflito

Sem dúvidas essa grande demanda oriunda do lado brasileiro apresenta-se como um tema de conflito e, portanto um empasse e desafio à gestão na bacia do Quaraí, somando-se as características do solo na bacia, a dependência quase exclusiva da orizicultura e problemas relacionados a agrotóxicos oriundos dos efluentes das lavouras de arroz que dividem cenário com o caráter transfronteiriço de gestão.

Predominantemente associadas ao cultivo do arroz (Figuras A e B), estas lavouras estão relacionadas à maior disponibilidade hídrica, às áreas mais planas e à ocorrência de solos mais adequados para esta atividade (Planossolos e Gleissolos), portanto é praticada na porção de baixo curso da bacia hidrográfica.

O predomínio de atividades agropecuárias, amparada na criação de gado ovino e bovino, que se distribui de forma extensiva por toda a bacia hidrográfica do Rio Quaraí, e primariamente no cultivo de arroz, concentrado

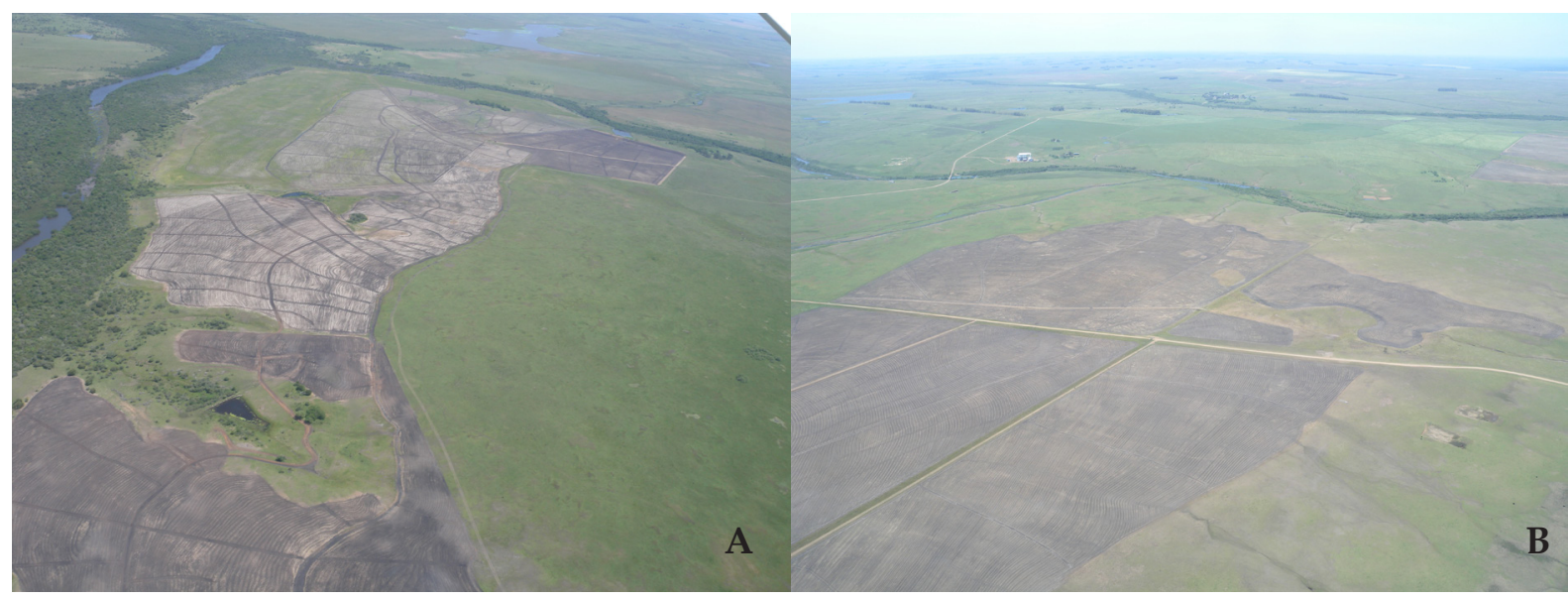

Figura 3. Cultivo de arroz na porção brasileira da bacia hidrográfica do Rio Quaraí - Fotografia obtida a partir de voo realizado em outubro de 2009. 
em sua porção oeste, principalmente no baixo curso do rio, somadas ao abastecimento urbano, geram conflitos quanto a demanda de água entre Brasil e Uruguai, nos períodos de déficit hídrico na bacia. Novillo (2005) na elaboração do relatório "Proyecto piloto demostrativo cuenca del "Río Cuareim/Quaraí" (Uruguay/Brasil)" reforça que

y en la cuenca del río Cuareim/Quaraí al Sur de Brasil y Norte de Uruguay, esta última afluente de la Cuenca del río Uruguay dentro del Sistema del Plata . Debido a la intensificación del cultivo del arroz en ambos países desde la década del 70 existe una fuerte demanda de agua para riego lo cual resulta en un potencial conflicto debido a la escasez del recurso en la cuenca (NOVILLO, 2005, p.1).

Entretanto, diferente das denominadas "fronteiras secas", a presença de rios atua antes como um elo entre países, do que um marco de separação, pois a gestão de recursos hídricos para ser eficiente deve transcender fronteiras e evitar medidas unilaterais.

Na tentativa de consenso e busca de soluções temos como marco legal um instrumento jurídico internacional, que constitui o acordo de cooperação entre o governo da República Oriental do Uruguai e o governo da República Federativa do Brasil para o aproveitamento dos recursos naturais e o desenvolvimento da Bacia do Rio Quaraí, firmado em Artigas, em 11 de março de 1991. Posteriormente, em 1996, foi realizado Estudo para o Conselho Estadual de Recursos Hídricos e encontra-se, também, em plena atividade o Comitê de Coordenação Local da Comissão Mista Brasileiro-Uruguaia para o Desenvolvimento da Bacia do Rio Quaraí (CCL/CRQ).

Mesmo que estes aportes legais estejam estabelecidos, de fato apresentam dificuldade para estabelecer uma gestão efetiva e conjunta entre os dois países, e como aponta Collischonn, (s/d) a bacia do Quaraí não possui um comitê de bacia, nos moldes da Política Nacional de Recursos Hídricos e a Agência Nacional de Águas (ANA) embora receba pedidos de outorga, a falta de um Plano de Bacia ou do conhecimento da disponibilidade hídrica, impedem estes pedidos de ser analisados.

\section{Conclusões}

Os levantamentos realizados junto aos órgãos de gestão e também outras pesquisas já realizadas na bacia hidrográfica, apontaram a demanda diferenciada quanto à água, tendo em vista as porções brasileira e uruguaia.

O mapeamento de uso do solo veio ao encontro deste diagnóstico, pois permite analisar a distribuição espacial da atividade que mais demanda água, a orizicultura. Concentrada predominantemente no lado brasileiro e representando $19,9 \%$ do uso dos $46 \%$ do território, destoa dos $12 \%$ de áreas mapeadas como lavouras do montante de $54 \%$ da bacia hidrográfica sob domínio uruguaio.
Nesta perspectiva, a gestão integrada de bacias hidrográficas envolve a gestão da complexidade em um território e, portanto, deve-se considerar as dimensões sociais, ambientais e econômica para a identificação detalhada dos conflitos como das oportunidades na elaboração de ações e ferramentas de gestão. As dificuldades de fiscalização para verificação dos compromissos assumidos pelas partes também emerge como um grande desafio. É neste sentido que os setores sociais atuantes estão avançando.

A partir do exposto, fica claro a necessidade de abordagem no processo de gestão de recursos hídricos, de regras claras e consistentes, que levem em consideração as peculiaridades de cada bacia contribuindo para a utilização harmoniosa dos recursos hídricos à escala da bacia hidrográfica, promovendo o uso racional e equitativo da água e, assim, ajudar a superar os conflitos entre usuários o recurso, incluindo o uso da agricultura irrigada. Isto evidencia a importância do sistema de gestão de recursos hídricos ser descentralizado, integrado, participativo e, sobretudo, transparente.

Ainda destacamos, que as técnicas de sensoriamento remoto e geoprocessamento e seus produtos, são ferramentas que podem ser utilizadas tanto no diagnóstico como na tomada de decisões pelos órgãos gestores.

\section{Referências}

ANA, Gestão Transfronteiriça Integrada da Bacia do Rio Quaraí/Cuenca del Rio Cuareim - Uruguay e Brasil, Workshop Quaraí, março de 2003.

BRASIL. Panorama e Estado dos Recursos Hídricos do Brasil. V. I. Ministério do Meio Ambiente. Secretaria de Recursos Hídricos. Brasília, 2006.

BRASIL. Plano Nacional de Recursos Hídricos - Síntese executiva. Ministério do Meio Ambiente, Secretaria de Recursos Hídricos. Brasília: MMA, 2006.

CALHMAN, O. K. B. Gestão de Recursos Hídricos em Bacias de Rios Fronteiriços e Transfronteiriços - Rio Quaraí/Bacia do Prata. Rio de Janeiro: UFRJ/COPPE, 2008.

CÂMARA, G. e MEDEIROS, J.S. Geoprocessamento para Projetos Ambientais. INPE, São José dos Campos, SP, 1996.

COLLISCHONN, Bruno. PAIVA, Rodrigo Cauduro Dias de. COLLISCHONN, Walter. MEIRELLES, Fernando Setembrino Cruz. CAMAÑO SCHETTINI, Edith Beatriz. FAN, Fernando Mainardi. Modelagem hidrológica de uma bacia com uso intensivo de água: caso do rio Quaraí - RS. In: Rbrh: revista brasileira de recursos hídricos. Porto Alegre, RS Vol. 16, n. 4 (out./dez. 2011), p. 119-133, il.; gráfs.; tab 
COLLISCHONN, Bruno. COLLISCHONN, Walter. Classificação multitemporal de uso do solo usando imagens CBERS para fins de simulação e gerenciamento de recursos hídricos na bacia do rio Quaraí. Anais XIV Simpósio Brasileiro de Sensoriamento Remoto, Natal, Brasil, 25-30 abril 2009, INPE, p. 4687-4692.

FERREIRA, J. F.; Geoprocessamento como Ferramenta na gestão pública municipal. Relatório de estágio (Graduação em geografia) Universidade federal de Santa Maria, Santa Maria, 2010.

LANDIS, J.; KOCH, G. The measurement of observer agreement for categorical data, Washington, USA. Biometrics, v. 33, n. 1, p. 159-174, 1977.

NOVILLO, J.M.G., PEREYRA, A., Programa Marco para la Gestion Sostenible de Los Recursos Hidricos de la Cuenca del Plata, en Relacion con los Efectos Hidrológicos de la Variabilidad y el Cambio Climatico. Proyecto Piloto Demostrativo Cuenca del "Rio Cuareim/Quarai" (Uruguay/Brasil) - Informe Final - Versión 3.1, Buenos Aires, Argentina. 2005

PROGRAMA DAS NAÇÕES UNIDAS PARA O DESENVOLVIMENTO, Relatório do Desenvolvimento Humano 2006. 1 UN Plaza, New York, New York, 10017, USA, 2006

RIGHI, Eléia (2011). Risco a inundação em médio curso do Rio Uruguai: um estudo de caso nos municípios de Porto Lucena e São Borja Dissertação (Mestrado em Geografia) - Universidade Federal do Rio Grande do Sul, Porto Alegre, 2011.

TUCCI, C. E. M. Visão dos recursos hídricos na bacia do Prata. Rega / Global Water Partnership South America. - Vol. 3, no. 2, p. 43-63, jul./dez. 2006

TUCCI, C. E.M..Visão dos Recursos Hídricos da Bacia do Rio da Prata, Visão Regional. Programa Marco para a Gestão Sustentável dos Recursos Hídricos da Bacia do Prata. GEF/CIC/PNUMA/OEA. 2004..

VILLANUEVA, A. O. N., VIEGAS, J. S., TRÖGER, F.H., 2002, Gestão Integrada de Inundações na Bacia Hidrográfica do Rio Quaraí / Cuareim (Brasil/Uruguai). Recompilação das Informações Básicas Existentes e Diagnóstico Preliminar (lado brasileiro). IPH/UFRGS, Global Water Partnership, Organização Meteorológica Mundial.

SANO, E. E.; ASSAD, E. D.; ORIOLI, A. L. Monitoramento da ocupação agrícola. In: ASSAD, E. D.; SANO, E. E. Sistema de informações geográficos: aplicações na agricultura. 2. ed. Brasília: Embrapa-SPI, 1998. p. 179-190. 